\title{
Preparação de cabelo caucasiano como material carbonoso
}

\author{
Preparation of caucasian hair as carbonaceous material
}

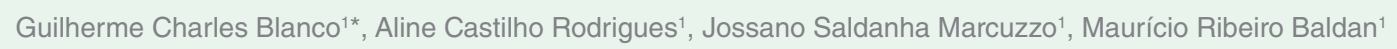

\section{RESUMO}

Este trabalho apresenta as etapas de preparação do cabelo caucasiano para posterior carbonização e sua transformação como material carbonoso, tendo em vista a produção de material carbonoso ativado a partir de matéria-prima proveniente de resíduos. Algumas das etapas consistem na conversão do cabelo em feltro e a posterior oxidação, com objetivo de eliminar o córtex e promover ligações cruzadas entre as cadeias de proteínas; esse processo permite transformar o cabelo em material termofixo, além de promover a evaporação do córtex capilar, deixando o filamento oco. Como etapa sequente, temos a carbonização e a ativação do material obtido. Tais condições indicam que o cabelo caucasiano pode tornar-se uma fibra de carbono ativada de alta área de superfície e elevada capacidade de adsorção, características desejáveis para uma futura aplicação como peneira molecular.

Palavras-chave: Cabelo, Oxidação Térmica, Fibra de Carbono.

\section{ABSTRACT}

This work presents the steps preparation of the Caucasian hair, for later carbonization and its transformation as carbonaceous material, aiming the production of a carbonaceous material activated from a raw material coming from residues. Some of the steps are the conversion of hair into felt and the subsequent oxidation which aims to eliminate the cortex and promote crosslinking between the protein chains. This process allows the hair to be transformed into a thermoset, as well as to promote evaporation of the hair cortex, leaving the hollow filament. As a sequential step, carbonization and activation of the obtained material was carried out. Such conditions indicate that Caucasian hair can become an activated carbon fiber of high surface area and high adsorption capacity, desirable characteristics for a future application as molecular sieve.

Keywords: Hair, Thermal Oxidation, Carbon Fiber. 


\section{INTRODUÇÃO}

O carbono ativado (CA) é um dos materiais adsorventes mais utilizados devido à sua ampla capacidade de atuação, que vai desde o tratamento de água e águas residuais à peneira molecular. Muitos estudos utilizam a natureza fibrosa proveniente de biomassa para produzir fibras de carbono. Para esse caso, os precursores orgânicos podem ser juta, coco, cânhamo, linho, fibra de coco e algodão de fibras naturais de seda ou sintéticas, como rayon. Os sintéticos podem ser provenientes de resinas fenólicas, poliamidas, poliacrilonitrila (PAN), piche mesofásico, entre outros. Tais precursores podem ser transformados em tecidos ou feltros, facilitando a manipulação ${ }^{1,2}$.

Estudos na viabilização do uso de fibras animais na produção de material ativado mostram a conversão da lã de ovelha em pó fino de CA3. Entretanto, existem trabalhos recentes que mostram a possibilidade de produzir uma fibra ativada oca a partir de lã de ovelha e alpaca ${ }^{4,5}$. Os trabalhos relatam, basicamente, a conversão da estrutura bicomponente (córtex/cutícula) em um cilindro oco.

O cabelo humano é uma fibra semelhante à lã de ovelha e está disponível como resíduo gerado em salões de beleza. O interesse mais comum, quando falamos em cabelo, é no crescimento, tipos e cuidados, sempre referentes à estética. Entretanto, é também um importante biomaterial composto, em média, de 51\% de carbono, $17 \%$ de nitrogênio, $21 \%$ de oxigênio, $6 \%$ de hidrogênio, $5 \%$ de enxofre e vestígios de metais. Amplamente, a fibra capilar é composta de proteínas queratinas, água, lipídios, pigmento e oligoelementos $^{6}$ e é um material complexo não homogêneo que pode ser associado a um polímero ${ }^{7}$.

O corpo da fibra capilar é dividido em três principais regiões medula (quando presente), córtex e cutícula - representadas pelo diagrama esquemático da Fig.1. Essas regiões são diferenciadas, principalmente, pelo tipo de proteína que cada uma é composta. Seu diâmetro pode variar de 45 a $110 \mu \mathrm{m}^{6,8,9}$.

As proteínas do cabelo pertencem aos grupos da escleroproteína e são compostos extremamente resistentes à ação de agentes físicos, químicos e biológicos ${ }^{10}$. Essa propriedade robusta assegura ao cabelo persistir em diversos tipos de ambientes deposicionais ${ }^{11}$.

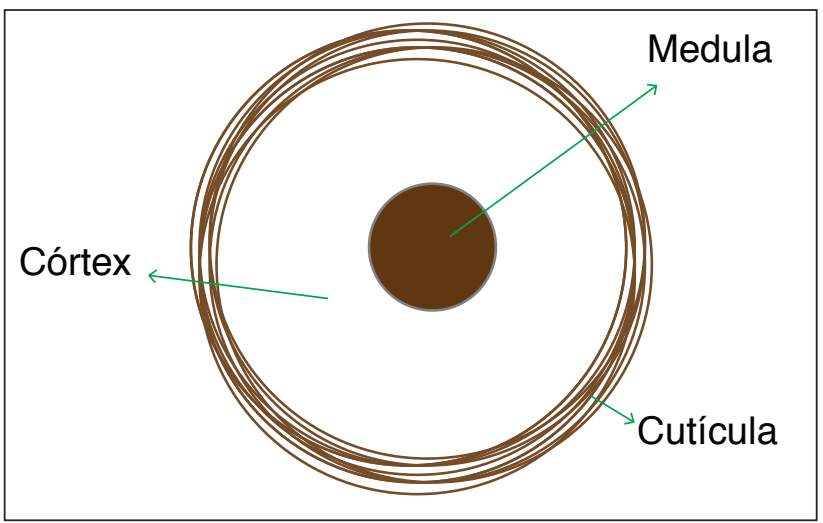

Figura 1: Representação esquemática do corte transversal de uma fibra capilar com medula.
De acordo com a Associação Brasileira de Normas Técnicas $(\mathrm{ABNT})^{12}$, o cabelo pode ser classificado como resíduo não perigoso, classe II B-Inerte, encontrado em efluentes ou em resíduos urbanos ${ }^{13}$.

Atualmente, muitos pesquisadores direcionam esforços com o intuito de buscar soluções para diversos problemas ambientais e diminuição de resíduos, sejam sintéticos ou orgânicos. As fibras capilares, como resíduos orgânicos, apresentam potencial de aproveitamento como material carbonoso. Este trabalho apresenta a transformação do cabelo caucasiano, o mais comum no Brasil, em material oxidado para posterior carbonização, visando a ser um material precursor alternativo para fabricação de fibras de CA.

\section{MATERIAIS E MÉTODOS Preparação do Feltro}

Em todo o trabalho, utilizou-se cabelo internacionalmente conhecido como de origem caucasiana, da cor castanha escura e natural, ou seja, jamais submetido a qualquer processamento químico (descoloração, permanente, alisamento ou coloração). Os fios, oriundos de um mesmo couro cabeludo, foram fornecidos por Studio Tata Blanco. A mecha, com comprimento de $20 \mathrm{~cm}$, foi lavada com xampu antirresíduos e secada ao ar. Após a secagem, foi submetida ao processo de feltragem manual. Nesse processo, o cabelo foi colocado sobre uma superfície esponjosa e, com auxílio de uma agulha para feltrar, trabalhou-se o material até obter-se uma estrutura firme como feltro em formato ovalado de cerca de $20 \times 10 \mathrm{~cm}$, conforme apresentado na Fig. 2 .

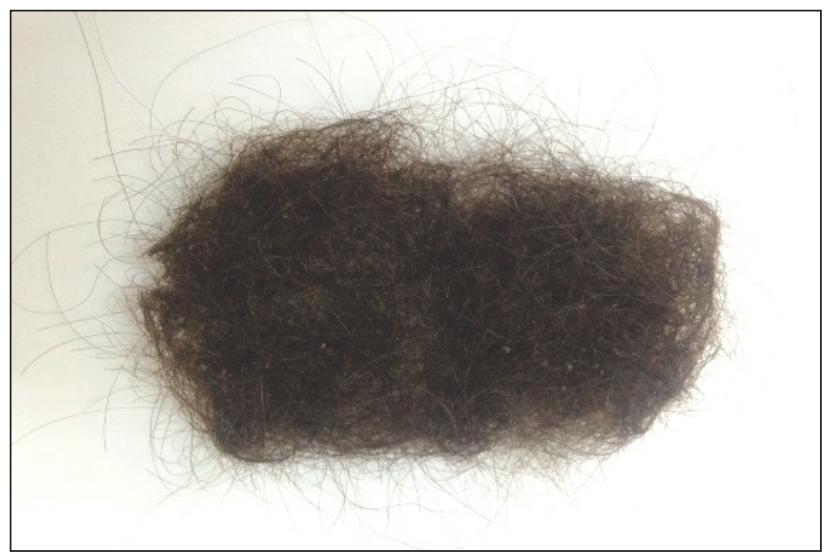

Figura 2: Feltro de cabelo caucasiano.

\section{Etapa de Oxidação}

$O$ feltro de cabelo foi cortado em formato retangular, com aproximadamente $40 \times 34 \mathrm{~mm}$. A amostra foi pesada e posteriormente colocada em um forno tubular, da marca EDG, modelo HI40, dentro de um tubo de quartzo (aberto) para oxidação à temperatura de $300{ }^{\circ} \mathrm{C}$. Esses parâmetros foram determinados em trabalhos anteriores $^{4,5}$. 


\section{Avaliação Morfológica da Superfície por Microscopia Eletrônica de Varredura com Emissão de Campo}

A amostra de feltro de cabelo foi caracterizada por Field Emission Gun (FEG-SEM), marca TESCAN, modelo VEGA 3. Nessa técnica, analisaram-se a topografia externa e a seção transversal dos filamentos das fibras.

\section{Microscopia de Força Atômica)}

Para obtenção de imagens de Microscopia de Força Atômica (Atomic Force Microscope - AFM, utilizou-se o equipamento da marca Veeco ${ }^{\circledR}$, modelo Mult Mold 5. As imagens foram obtidas pelo modo contato, utilizando-se agulha de nitreto de silício com constante de força de $0,036 \cdot \mathrm{Nm}^{-1}$. As micrografias foram obtidas com comprimento de varredura de $2 \times 2 \mu \mathrm{m}$ e resolução de $512 \times 512 \mathrm{Px}$.

\section{RESULTADOS \\ Análise Morfológica}

Nas Figs. 3A, 3B e 3C, são apresentadas as micrografias do cabelo in natura nas quais podem-se observar as estruturas mais preservadas, maciças e sem defeitos, típicas de um cabelo saudável, com regiões tanto da cutícula quanto do córtex bem definidas.

As micrografias apresentadas na Figs. 3D, 3E e 3F são referentes à fibra oxidada. Observa-se a ausência do córtex em seu interior, o que é esperado, uma vez que o processo de oxidação volatiliza algumas estruturas, tornando a fibra oca em formato de tubo ${ }^{3-5}$. Também é possível visualizar que as cutículas aparentam estar fundidas. Contudo, não é possível afirmar, pela micrografia apresentada, que haja uma superfície porosa.
A fim de conhecer topograficamente a superfície das amostras, realizaram-se análises de AFM. A cor da imagem não tem nenhuma relação com a estrutura analisada, apenas um contraste de alturas na representação dessa amostra. Deve-se levar em conta a intensidade da cor, pois os pontos mais claros indicam menores distâncias entre o cantilever e amostra durante a varredura.

Nas Figs. 4A e 4B, podem ser observadas as imagens 2D e 3D, respectivamente, com dimensão de $4 \mu \mathrm{m}^{2}$ da superfície da fibra

(A)

(B)
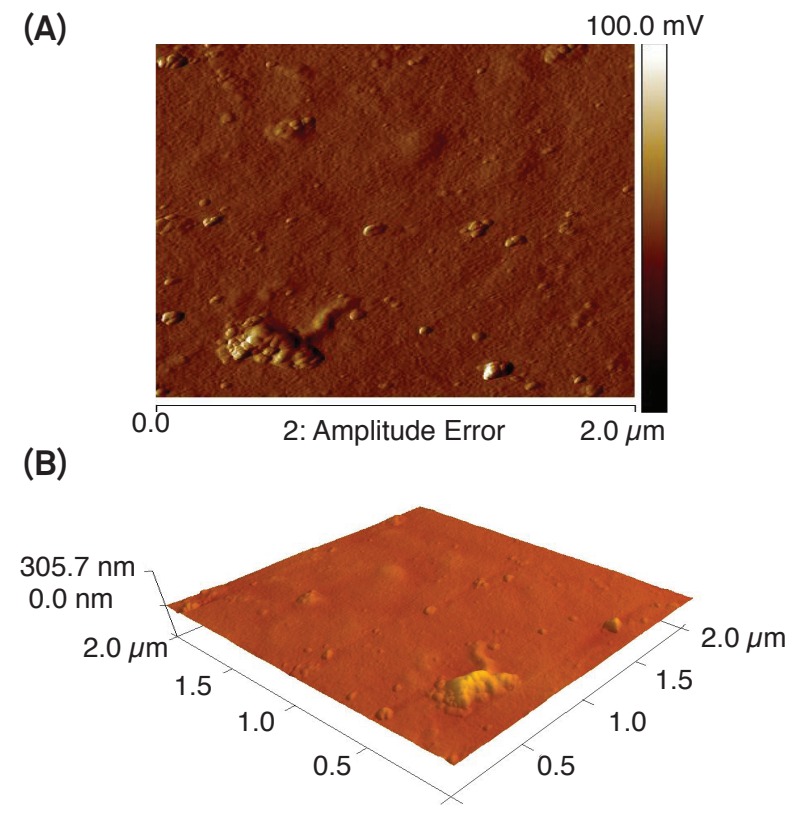

Figura 4: Imagens de AFM da superfície da fibra de cabelo oxidada a $300^{\circ} \mathrm{C}$. (A) imagem 2D; (B) imagem 3D.
(A)

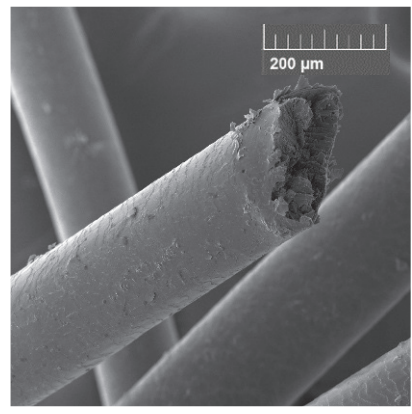

(D)

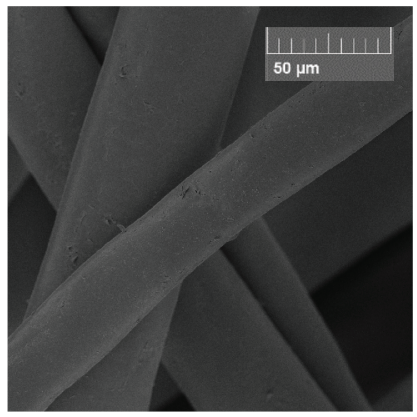

(B)

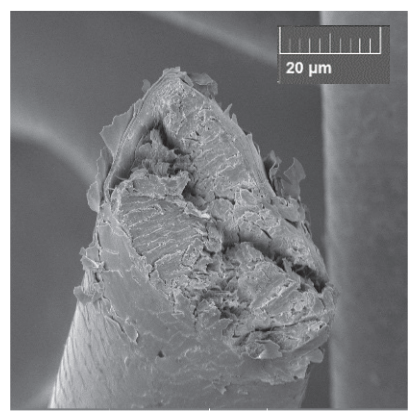

(E)

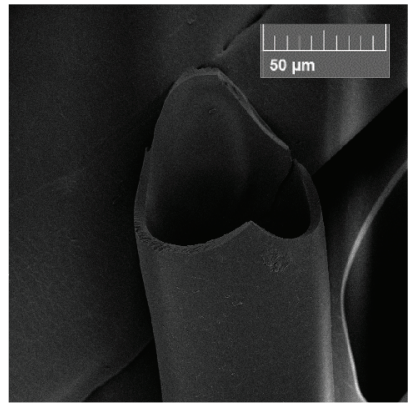

(C)

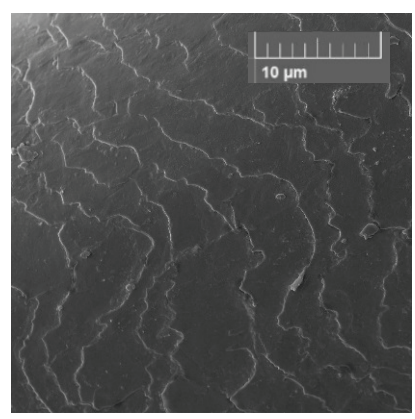

(F)

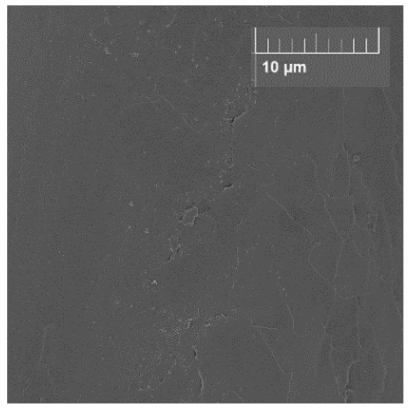

Figura 3: Imagens obtidas de FEG-SEM da amostra de feltro de cabelo caucasiano natural. (A, B, C) material de partida; (D, E, F) material após oxidação. 
de cabelo oxidada. Na superfície, é notável a presença de algumas estruturas arredondadas com diâmetro equivalente médio de $50 \mathrm{~nm}$. Essas estruturas podem ter surgido devido a possíveis erosões causadas pelo processo de oxidação. Também é possível perceber que a superfície se encontra íntegra e livre de defeitos (fissura, descontinuidades), além disso a rugosidade média aritmética encontrada foi de $3,87 \mathrm{~nm}$.

Esse método de produção provavelmente é economicamente eficiente, já que o método de fabricação e a respectiva rota são os mesmos para todas as matérias-primas, por meio de fibras naturais vegetais e animais. Comparando-se esses dois tipos, as diferenças são a quantidade superior de poros e a formação de um tubo nas fibras animais, ou seja, melhor eficiência na aplicação. Dentre as fibras de caráter animal, existe pesquisa somente com lã de ovelha. A lã tem o custo da importação e do próprio valor de mercado; em comparação, o cabelo, não tem custo algum, pois é considerado resíduo encontrado em salões de beleza.

\section{CONCLUSÕES}

O trabalho de feltragem apresentou resultados que indicam a viabilização da transformação do cabelo em artefato têxtil.

Após a oxidação, o cabelo caucasiano em questão manteve sua estrutura dimensional e houve a perda do córtex. Além disso, apresentou uma superfície íntegra com ausência de danos estruturais. Essa etapa é fundamental no processo de conversão de matéria-prima carbonosa.

Os resultados indicam que o cabelo humano caucasiano é promissor como material carbonoso ativado após o processo de conversão, com potencial para aplicação em diversas áreas, como, por exemplo, andaime para célula óssea e peneira molecular.

\section{REFERÊNCIAS}

1. Darmstadt H, Ryong R, Ryoo R. Adsorption on ordered porous carbons. In: Bottani EJ, Táscon JMD, editors. Adsorption by carbons. Elsevier; 2008. p. 455-77. https://doi.org/10.1016/B9780-08-044464-2.X5001-9

2. Marsh $\mathrm{H}$, Rodríguez-Reinoso F. Porosity in carbons: modeling. In: Marsh H, Rodríguez-Reinoso F. Activated carbon. Elsevier; 2006. p. 87-142. https://doi.org/10.1016/B978-0-08-044463-5.X5013-4

3. Chen W, Liu X, He RL, Lin T, Zeng QF, Wang XG. Activated carbon powders from wool fibers. Powder Technol. 2013;234:7683. https://doi.org/10.1016/j.powtec.2012.09.026

4. Pina A, Amaya A, Marcuzzo JS, Rodrigues AC. Supercapacitor electrode based on activated carbon wool felt. C. 2018;49(2)24. https://doi.org/10.3390/c4020024

5. Pina A, Tancredi N, Baldan M, Marcuzzo JS. $\mathrm{CO}_{2}$ capture and biomethane obtention using activated carbon filter of animal origin. MRS Adv. 2018;3(61)3589-3600. https://doi.org/10.1557/ adv.2018.588

6. Robbins CR. Chemical and physical behavior of human hair. Berlin/Heidelberg: Springer Berlin Heidelberg; 2012. https://doi. org/ 10.1007/978-3-642-25611-0 2

7. Saxena M, Pappu A, Sharma A, Haque R, Wankhede S. Composite materials from natural resources: recent trends and future potentials. In: Tešinova P. Advances in composite materials - Analysis of natural and man-made materials. Rijeka: IntechOpen; 2011. p. 133-174.

8. Bhushan B. Biophysics of human hair. Structural, nanomechanical and nanotribological studies. Berlin/Heidelberg: Springer Berlin Heidelberg; 2010. https://doi.org/10.1007/978-3-642-15901-5

9. Jolles $\mathrm{P}$, Zahn $\mathrm{H}$, Hoecker $\mathrm{H}$. Formation and structure of human hair. Birkhäuser: Verlag; 1997.

10. Masih H, Singh S. Degradation of keratinous waste products by keratinolytic bacteria isolated from soil. J Eng Comput Sci. 2014;3:7588-95.

11. Birch MP, Messenger JF, Messenger AG. Aging hair. Berlin/ Heidelberg: Springer Berlin Heidelberg; 2010. https://doi. org/10.1007/978-3-642-02636-2

12. Associação Brasileira de Normas Técnicas. NBR 1004: Resíduos sólidos - Classificação. Rio de Janeiro: ABNT; 2004.

13. Verma A, Singh VK. Human hair: a biodegradable composite fiber - A review. IJWR. 2016;6(2)2-5. https://doi.org/10.4172/22525211.1000206 